\title{
Association between atrial fibrillation and Helicobacter pylori
}

\author{
Cecilia Tetta $^{1} \cdot$ Amalia loanna Moula $^{1} \cdot$ Francesco Matteucci $^{1} \cdot$ Orlando Parise $^{1} \cdot$ Bart Maesen $^{1} \cdot$ Daniel Johnson $^{1}$. \\ Mark La Meir ${ }^{1}$. Sandro Gelsomino ${ }^{1}$
}

Received: 5 December 2018 / Accepted: 22 January 2019 / Published online: 8 February 2019

(C) The Author(s) 2019

\begin{abstract}
The connection between atrial fibrillation (AF) and H. pylori (HP) infection is still matter of debate. We performed a systematic review and metanalysis of studies reporting the association between AF and HF. A systematic review of all available reports in literature of the incidence of HP infection in AF and comparing this incidence with subjects without AF were analysed. Risk ratio and 95\% confidence interval (CI) and risk difference with standard error (SE) were the main statistics indexes. Six retrospective studies including a total of 2921 were included at the end of the selection process. Nine hundred-fifty-six patients (32.7\%) were in AF, whereas 1965 (67.3\%) were in normal sinus rhythm (NSR). Overall, 335 of 956 patients with AF were HP positive (35\%), whereas 621 were HP negative (65\%). In addition, 643 of 1965 NSR patients (32.7\%) were HP positive while 1,322 were negative (67.3\%; Chi-square 2.15, $p=0.21$ ). The Cumulative Risk Ratio for AF patients for developing an HP infection was 1.19 (95\% CI 1.08-1.41). In addition, a small difference risk towards AF was found $(0.11$ [SE $=0.04])$. Moreover, neither RR nor risk difference were influenced by the geographic area at meta-regression analysis. Finally, there was a weak correlation between AF and HP (coefficient $=0.04$ [95\% CI $-0.01-0.08]$ ). We failed to find any significant correlation between $\mathrm{H}$. pylori infection and AF and, based on our data, it seems unlikely than HP can be considered a risk factor for AF. Further larger research is warranted.
\end{abstract}

Keywords Atrial fibrillation $\cdot$ Helicobacter pylori $\cdot$ Metanalysis

\section{Introduction}

Despite better knowledge of the pathophysiology of atrial fibrillation(AF) [1-17] and significant advances in ablation techniques [18-26], its incidence is rising worldwide [27], resulting in a dramatically increased social and economic burden on the healthcare system [28-31].

The pathophysiology of AF is complex [32] and it has been found to be associated with inflammation as well as other non-cardiac pathologies [33-35]. Among these, gastrointestinal (GI) disorders share with AF some risk factors such as stress, smoking and inflammation as well

Cecilia Tetta and Amalia Ioanna Moula have contributed equally to this work.

Sandro Gelsomino

sandro.gelsomino@maastrichtuniversity.nl

1 Department of Cardiothoracic Surgery, Cardiovascular Research Institute Maastricht -CARIM, Maastricht University Medical Centre, Universiteitssingel 50, 6229 ER Maastricht, The Netherlands as some common symptoms such as chest pain and faintness [36] and they have often been described in association with AF [37].

In particular, Helicobacter pylori (HP) infection has been strongly linked to AF by previous studies leading to the hypothesis that HP could be the cause of AF through systemic inflammatory response [37-39]. Nonetheless, this connection has been questioned by other authors and it is still matter of debate [40, 41]. Furthermore, available metanalyses include other supra-ventricular arrhythmias other than AF [42] or include other infections associated to $\mathrm{AF}$ [39].

Therefore, to test the hypothesis whether there is a causal relation between $\mathrm{AF}$ and the infection of $\mathrm{HP}$, we performed a systematic review and metanalysis of the studies published reporting this association. 


\section{Materials and methods}

\section{Search strategy}

Literature search was conducted in accordance with the Preferred Reporting Items for Systematic Review and Metanalyses (PRISMA) [43]. An unrestricted literature search was performed using PubMed, EMBASE, Web of Science and Google Scholar Databases, as well as well as congress proceedings from major cardio cardiothoracic and cardiology societies meetings.

Search terms were: "Atrial Fibrillation" OR "Atrial Fibrillation AND Gastritis" OR "Atrial Fibrillation AND Helicobacter pylori”, OR “Atrial Fibrillation AND stomach" OR “Atrial Fibrillation AND Digestive Disease" OR "Atrial Fibrillation AND Digestive Disorders" OR “Arrhythmias AND Gastritis" OR "Arrhythmias AND Helicobacter pylori", OR "Arrhythmias AND stomach" OR "Arrhythmias AND Digestive Disease" OR "Arrhythmias AND Digestive Disorders".

The search strategy was decided by two authors (C.T. and A.I.M.) and approved by another reviewer (B.M.). The literature was limited to articles published in English. References of original articles were reviewed manually and crosschecked for other relevant reports.

\section{Selection criteria and quality assessment}

Studies were included if they met all of the following criteria: (1) human studies; (2) full articles about AF and HP having a non-AF control population; (3) adequate information regarding the positivity to HP infection. Exclusion criteria were: (1) animal studies; (2) case report; reviews; (5) lack of information for meta-analysis.

Two authors (A.I.M. and C.T.) selected the study for inclusion, extracted studies, as well as patient information and outcomes. Two reviewers (S.G. and M.L.M.) independently assessed eligibility of the studies and risk of bias. Risk of bias at the individual study level was assessed using ROBINS-I tool (Risk of Bias in No-randomized Studies-of Interventions) [44].

\section{Methodological quality assessment}

The quality of included studies was assessed using a rating scale based on Downs and Black's Checklist for Measuring Quality [45]. This rating scale for non-randomized designs was recently adapted for use in meta-analytic research on interpretation biases toward illness-related information [46]. The ratings scale consisted of 18 items assessing the quality in terms of reporting, external validity, internal validity, confounders, and power of the study. Each criterion is rated on a two-point scale (0/no, 1/yes), with exception of item 11 ("confounders described and controlled for") that has a score ranging from 0 to 2 , with higher scores indicating superior quality. Two independent researchers (F.M. and O.P) conducted the ratings. Any divergences were resolved by a third reviewer (B.M) and quantified using the Cohen's kappa [47, 48].

\section{Endpoints}

The primary endpoint was HP infection defined as diagnosed infection either by biopsy-based tests including histological evaluation, culture, polymerase chain reaction (PCR), and rapid urease test (RUT) or non-invasive procedure such as breath test (UBT), serology, and stool antigen test (SAT) [49].

\section{Statistical analysis}

Meta-analysis was conducted using Comprehensive Metanalysis v.2.2 (Biostat, Englewood, New Jersey) and Stats Direct v.3.0 (Stats Direct Ltd Cambridge, UK). Risk ratio and $95 \%$ confidence interval (CI) and risk difference with standard error (SE) were the main statistics indexes for binary outcomes. The statistical inconsistency test $\mathrm{I}^{2}$ was used to assess heterogeneity [50]. Nonetheless, because the high degree of heterogeneity anticipated among the available studies (only non-randomized trials) and inverse variance (DerSimonian Laird) an inverse-variance-random effect model was employed as a more conservative approach accounting for between- and within-study variability. Publication bias was evaluated graphically using a funnel plot and determined mathematically using Egger regression and the Begg-Mazumdar rank correlation test.

A correlation analysis was carried out using the Schmidt-Hunter method that provides the least biased estimate [51]. In addition, by means of meta-regression, the impact of the geographic area across single studies and its relationship to the occurrence of the primary endpoint was investigated. All p values $<0.005$ were considered statistically significant.

\section{Results}

\section{Characteristics of the studies}

The PRISM flow diagram describing the study selection process along with reasons for exclusion is shown in Fig. 1. The number of studies found was 258. Of these articles 229 were excluded as not related to the topic. Twenty-nine articles underwent further screening after exclusion of 14 double 


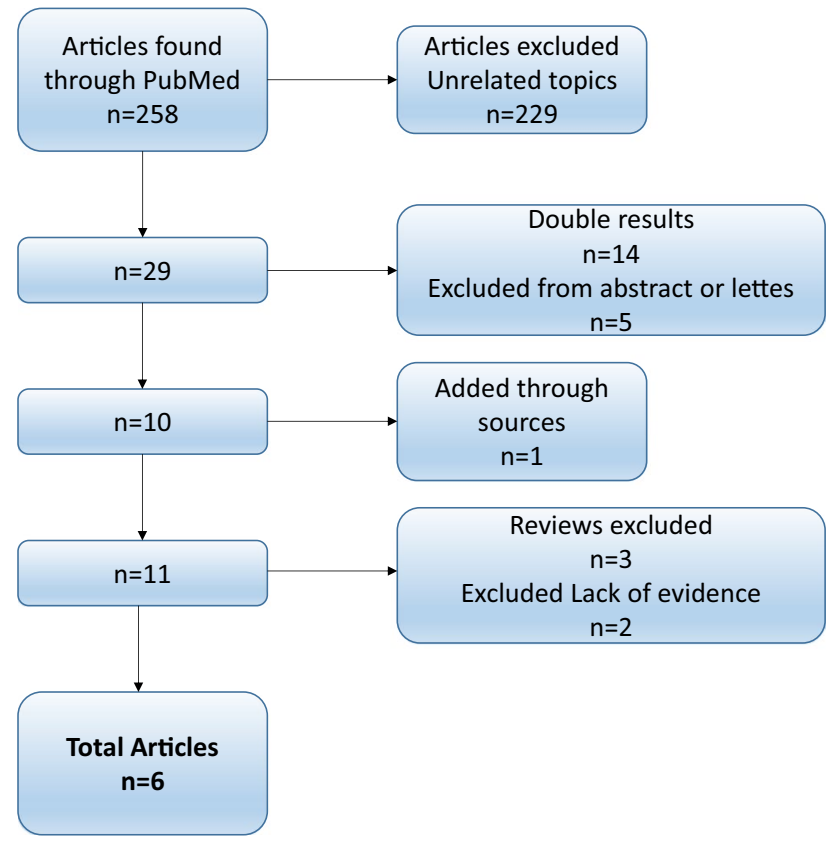

Fig. 1 PRISMA diagram of the study selection process

results, 10 were found to be on topic and suitable for further evaluation. One article was added from the references of the sources. Subsequently, 11 articles were further assessed. Of those four review articles and two articles that did not have appropriate end points and/or missing statistical data were excluded. After removal of reports not pertinent to the design of the current metanalysis, six retrospective observational studies that met explicit inclusion criteria remained, including a total of 2,921 patients [40, 41, 52-56]. Nine hundred-fifty-six patients (32.7\%) were in AF, whereas 1965 $(67.3 \%)$ were in normal sinus rhythm (NSR). Detailed characteristics of studies and patients are described in Table 1.

\section{Methodological quality}

The average overall quality rating was $0.81 \pm 0.26$ with ratings ranging from 0.58 to 1 . Table 2 presents the average scores on the items of the checklist. The table reveals lower scores for the item assessing whether the studies tested participants' engagement with the task(s) and items related to the quality of reporting (confounders, exact probability values, withdrawals/drop-outs, and power analysis). Acceptable inter-rater agreement was found $(\kappa=0.74)$.

\section{Main endpoint}

All the seven selected studies contributed to the analysis. Table 3 shows HP diagnostic criteria. In the overall analysis (Fig. 2), 335 of 956 patients with AF were HP positive (35\%), whereas 621 were HP negative $(65 \%)$. In addition,
643 of 1,965 NSR patients (32.7\%) were HP positive while 1322 were negative $\left(67.3 \% ; \chi^{2} 2.15, p=0.21\right)$.

The cumulative risk ratio (Fig. 3a) for AF patients for developing an HP infection was 1.19 (95\% CI 1.08-1.41). In addition, a small difference risk (Fig. 3b) towards AF was found $(\mathrm{RD}=0.11[\mathrm{SE}=0.04])$. Moreover, neither $\mathrm{RR}$ nor risk difference was influenced by the geographic area (Fig. 3c, d) at meta-regression analysis.

There was significant heterogeneity in the selected studies $\left(I^{2}=63.6 \%, p=0.011\right)$, thus the random-effect model was employed. No publication bias was observed in the funnel plot (Fig. 4) and as confirmed in Egger's test for the asymmetry (intercept $-0.91,95 \% \mathrm{CI}-3.8-5.7, p=0.62$ ) and Begg and Mazumdar test $(\tau=-0.04, p=0.88)$ that were not significant.

Finally, there was a weak correlation (Fig. 5) between AF and HP (coefficient $=0.04$ [95\% CI $-0.01-0.08]$ ). There was significant heterogeneity in the selected studies $\left(I^{2}=48 \%\right.$, $p=0.02$ ) thus the random-effect model was employed (Egger's test, intercept 1.5, 95\% CI $-1.8-4.9, p=0.30$; Begg and Mazumdar test, $\tau=-0.23, p=0.45$ ).

\section{Discussion}

Helicobacter pylori is a Gram-negative bacterium affecting nearly half of the world's population [49], but only a small percentage of infected patients develop more severe pathologies, such as ulcers (10-15\%) and stomach adenocarcinomas (less than 1\%) [57, 58].

The association between atrial fibrillation (AF) and Helicobacter pylori (HP) infection was first reported by Montenero et al. in 2005 who found higher levels of $\mathrm{IgG}$ antibodies in patients with AF compared to healthy volunteers [37].

This association was believed to be on an inflammatory basis and it has been postulated that the infection might be the substrate of the systemic inflammation manifesting in AF [38]. Indeed, there is strong evidence to support the influence of inflammation in the pathogenesis of atrial fibrillation [59] which is associated with increased levels of markers which reflect an underlying inflammatory process [60]. Actually, the levels of high-sensitivity C-reactive protein (hs-CRP) have been shown to be higher among patients with AF compared with controls in sinus rhythm [60] and the stronger association of HP and AF in patients with persistent AF [37] along with the demonstration that persistent AF patients have higher hs-CRP levels than paroxysmal AF patients [61], would further support the involvement of HP in the chronic atrial inflammation resulting in AF. However, in contrast with these authors, Marcus et al. [62] failed to find any association between atrial fibrillation and all inflammatory indices (C-protein, TNF-alpha, CD40 ligand, monocyte chemoattractant protein 1, fibrinogen) excluding IL-6. 







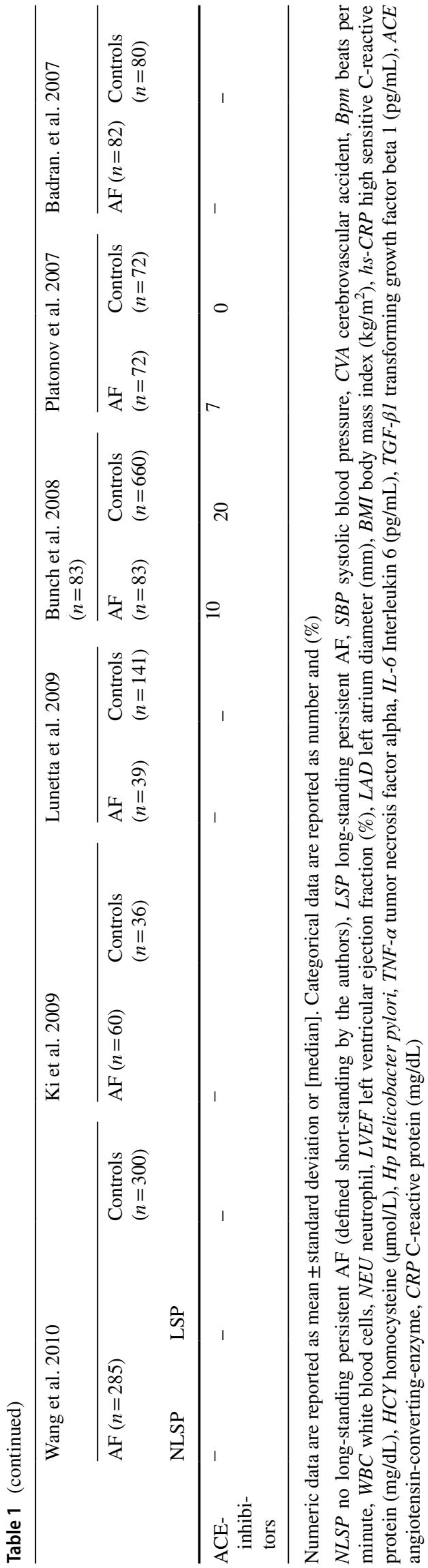

A recent study [63] has explained that the development of atrial cardiomyopathy, the results of complex of structural, architectural, contractile or electrophysiological changes affecting the atria, creates a substrate which can maintain AF. Nonetheless, not one specific risk factor but multiple concomitant modifiable cardiovascular risk factors determine the manifestation and progression of AF. Recent papers identify the alteration of the gut microbiota (dysbiosis) in most cardiovascular AF risk factors being responsible of AF progression through derived metabolites that affect atrial remodeling $[64,65]$. Nonetheless, whether and how dysbiosis might contribute to atrial remodeling and AF progression remains unknown.

Regarding the causal pathophysiologic mechanism, it has been postulated that, due to the similarity between $\mathrm{H}+/ \mathrm{K}+-$ ATPase of gastric and cardiac cells, autoantibodies to $\mathrm{H}+$ / $\mathrm{K}+$-ATPase would hamper the ATP hydrolysis and that this unbalance would trigger AF by determining depolarization delay and inducing premature atrial contractions [37].

The association of HP and AF was reported also by Whang et al. [56] in a Chinese population of 285 patients and by Franceschi et al. [55] who found an epidemiological link between HP and supraventricular dysrhythmias, including AF, and ventricular arrhythmias in 54 arrhythmic patients compared to 50 healthy controls. Finally, Bunch et al. [52] found that patients with AF were more likely to be seropositive for HP than the non-AF-control group. Furthermore, these authors report that younger patients $(<50$ years) showing a higher risk (8\%) of AF of those who were HP seropositive. Interestingly, although the oldest group had the highest overall incidence of AF, there was, among them, only a small increase in risk if they were seropositive for HP.

However, the association between HP and AF has been strongly argued by other studies and available reviews and metanalyses have not helped to solve the matter because of their limitations [39, 42].

For instance, Platonov et al. [41] who have reported no significant association between atrial fibrillation and $\mathrm{H}$. pylori infection in 72 patients with permanent $\mathrm{AF}$ compared 1:1 to controls, despite significantly higher levels of C-reactive proteins in these subjects. These authors stopped the patient recruitment for the study due to a constant reduction in differences between groups. In addition, Lunetta et al. [40] showed only a small difference in developing AF between HP-positive and HP-negative subjects (21\% vs. $18 \%$ ) thus excluding that inflammation induced from HP might be responsible of new-onset AF.

Our analysis confirms these findings: indeed, the pooled HR was very close to one with a $11 \%$ risk difference that it can be easily influenced by other factors not analyzed by papers (sex, familiarity, obesity, race, etc.). Furthermore, we found a weak correlation between the infection of HP and the development of AF (coefficient $=0.05$ ). 
Table 2 Quality assessment

\begin{tabular}{llll}
\hline & Item & $M$ & SD \\
\hline 1 & Study hypothesis/aim/objective described? & 1.00 & 0.00 \\
2 & Main outcomes described in the introduction or methods? & 0.97 & 0.16 \\
3 & Participant characteristics described? & 0.92 & 0.27 \\
4 & Contacted participants representative? & 0.87 & 0.33 \\
5 & Prepared participants representative? & 0.86 & 0.35 \\
6 & Participants recruited from the same population? & 0.70 & 0.46 \\
7 & Participants recruited over the same time? & 0.97 & 0.16 \\
8 & Measures and experimental tasks described? & 1.00 & 0.00 \\
9 & Main outcome measures valid and reliable? & 1.00 & 0.00 \\
10 & Task engagement assessed? & 0.33 & 0.50 \\
11 & Confounders described and controlled for? & 0.58 & 0.65 \\
12 & Statistical tests appropriate? & 1.00 & 0.00 \\
13 & Main findings described? & 0.97 & 0.16 \\
14 & Estimates of the random variability in data main outcomes? & 0.86 & 0.35 \\
15 & Probability values reported? & 0.58 & 0.50 \\
16 & Withdrawals and drop-outs reported? & 0.61 & 0.49 \\
17 & Data dredging made clear? & 0.92 & 0.27 \\
18 & Sufficient power analysis provided? & 0.80 & 0.27 \\
\hline
\end{tabular}

All items have a maximum score of 1.00 except item 11 has maximum score of 2.00

Therefore, from our data, it seems that there is no strong pathogenic link between the bacterial infection and the atrial arrhythmias. Hence, it seems more likely that remodeling and atrial damage lead to an increase in C-reactive protein rather than the opposite. This is also supported by the demonstration that such an increase occurs already at first AF onset and in paroxysmal AF [66], thus apparently excluding any etiopathogenetic role of the HP.

However, if further studies confirm that HP is not responsible either for the initiation or the maintenance of $\mathrm{AF}$, in accordance to our findings, the proposed eradication of HP infection as possible treatment for AF patients, proposed by some authors [38], it would not be even an option for these patients not only for its low cost-effectiveness, but also for the risk to further spread antibiotic resistance.

However, when HP arrives in the human stomach, it may penetrate the mucin layer and adhere to the gastric epithelial cells or it may pass through the stomach without colonizing the mucosa. In the stomach, after initial colonization, many chemical, biochemical, and immunologic reactions take place that are of importance in the progress of the infection and the development of disease [67].

In the major part of cases, infections are chronic, whereas acute $H$. pylori disease, lasting for a few weeks, and characterized by abdominal pain and infiltration of polymorph nuclear leucocytes in the gastric mucosa, is rarely described [67]. All papers included in this review reported HP-IgGpositivity, therefore we can assume that in all these patients B lymphocytes were activated by antigen-presenting cells and that a humoral immune response to $H$. pylori was initiated as response to HP infection.

Finally, an interesting finding of our metanalysis is that, in contrast with previous papers [42], the risk ratio of HP was not influenced by the geographic area. This difference might be due to the inclusion by these authors of one study including patients with idiopathic dysrhythmias, leading them to different conclusions. Said that our findings need to be read with caution since the small number of studies coming from Africa and America, these are not surprising. Indeed, the $H$. pylori infection rate is higher in Asia and Africa than that in western countries, in relation to different standards of hygiene and socioeconomics [5], whereas AF shows higher prevalence, disability-adjusted-life years (DALYs) and mortality in high-income countries than lowmiddle income and developing countries. This difference is significant, but it must be interpreted with caution since it might be related to under-reporting, limited access to health care services and geographically disparity in published data $[27,68,69]$.

Finally, the higher number of studies coming from western countries might justify the high AF prevalence reported (>30\%) and definitely higher than expected in the general population. However, inter-studies heterogeneity also regarding AF prevalence variability was addressed by the random-effect model used for metanalysis. 


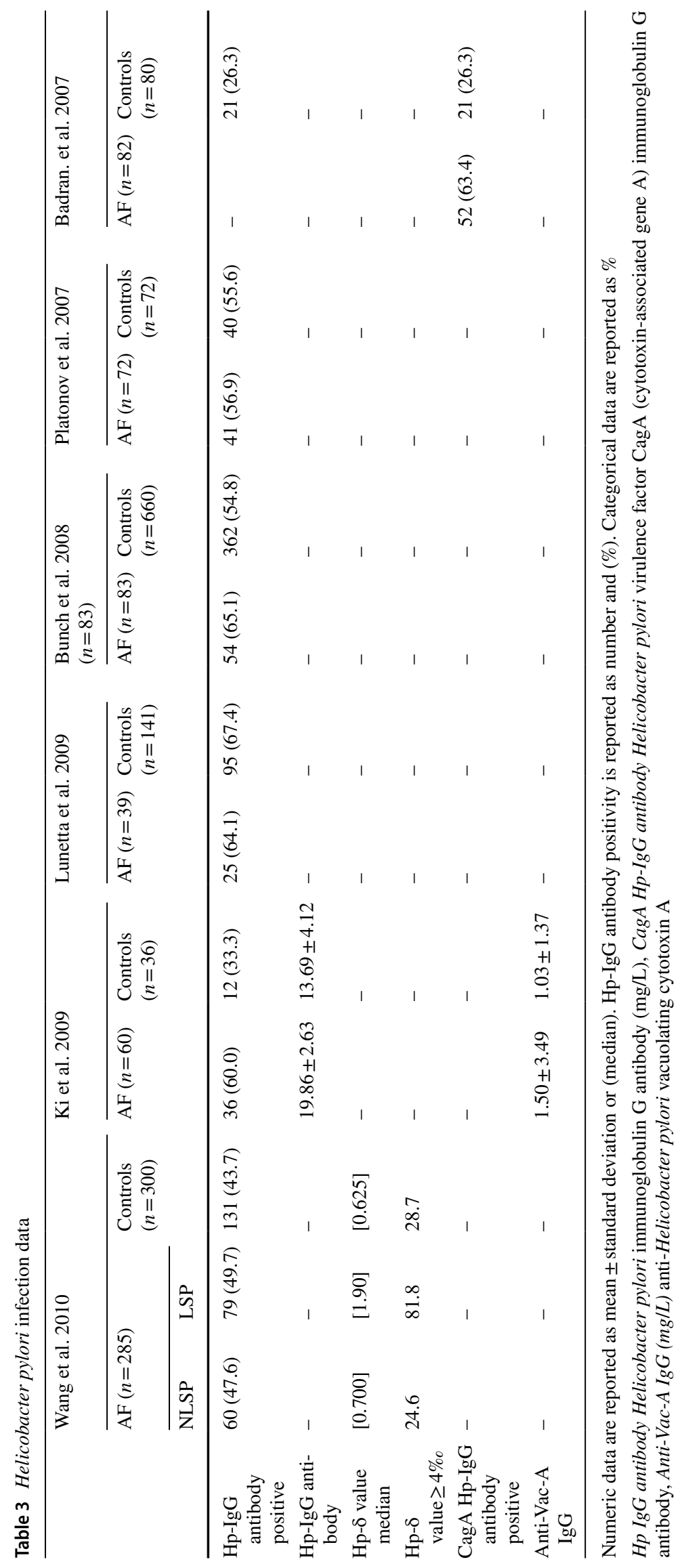




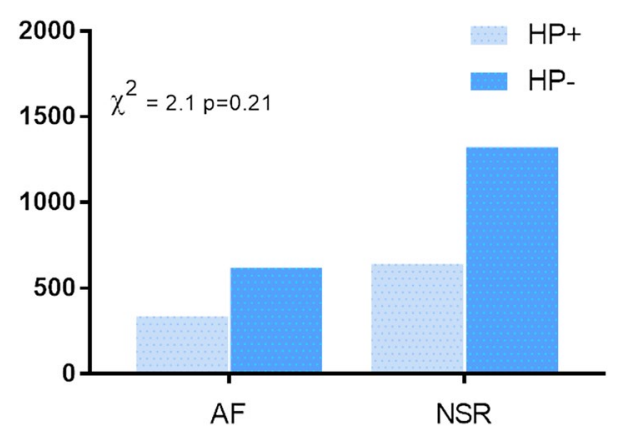

Fig. 2 H. pylori infection in patients with and without $\mathrm{AF}$

\section{Study limitations}

This metanalysis has some limitations that have to be pointed out.

Firstly, the number of studies is small, and all papers were case-control studies with high-degree of heterogeneity. Secondly, the number of studies in different geographic areas is too small to allow us to draw any final conclusion. Third, different diagnostic methods were employed for the diagnosis of HP infection and it is not reported if the infection is active. Fourth, only a few papers reported the analysis by AF type and this did not allow a subgroup analysis. Fifth, monitoring and detection of AF was not specified in the studies.
A
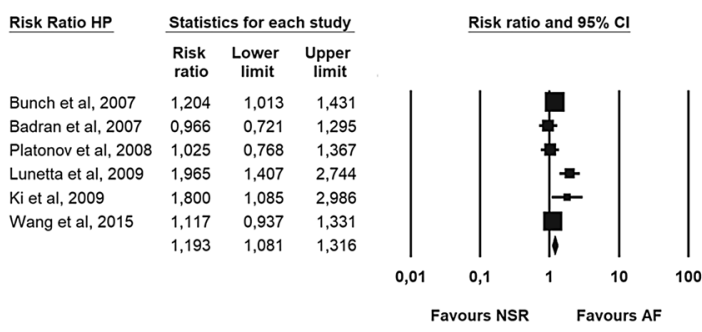

C

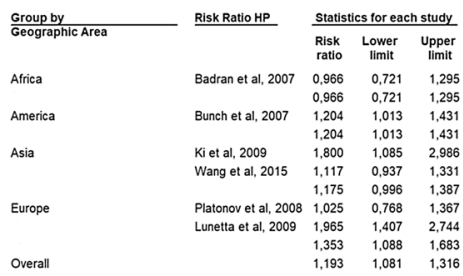

B

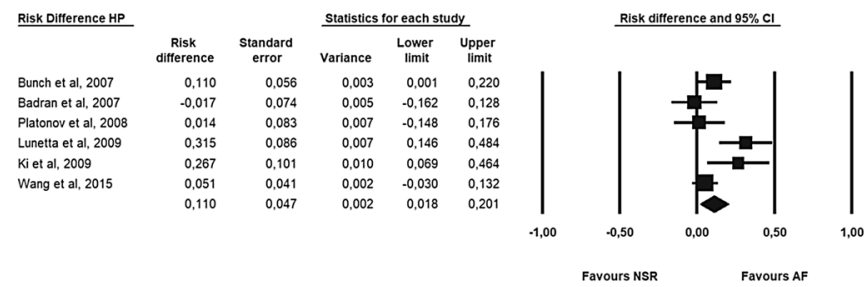

D

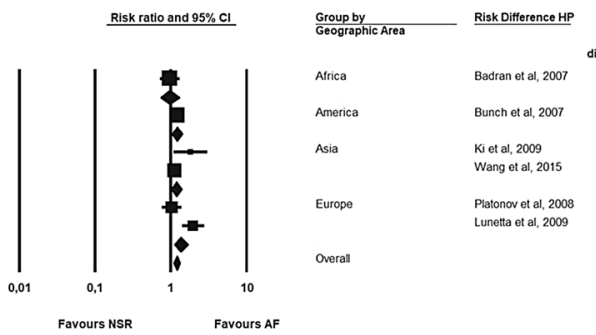

Fig. 3 Forest plot. a Risk ratio of HP in patients with AF. b Risk difference of HP incidence between patients with or without AF. $\mathbf{c}$ Risk ratio of HP in patients with AF by geographic area. d Risk difference of HP incidence between patients with or without AF by geographic area

Fig. 4 Funnel plot

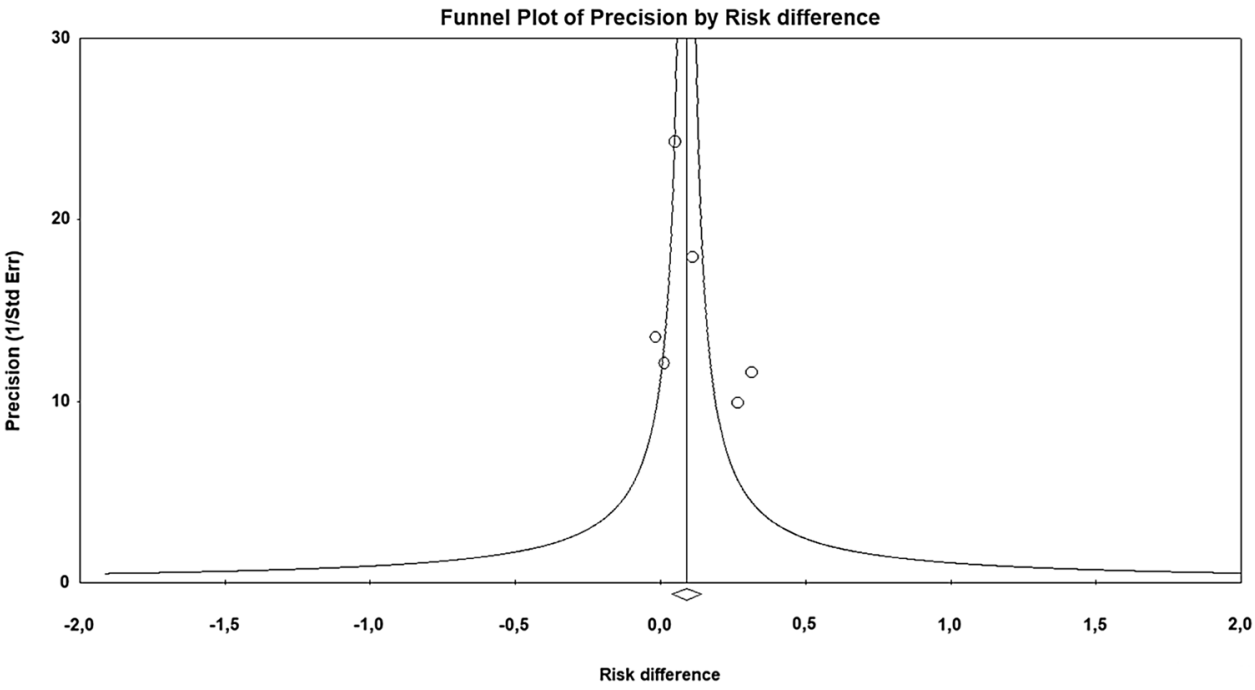




\begin{tabular}{lrrr} 
HP and AF & \multicolumn{3}{c}{ Statistics for each study } \\
\cline { 2 - 4 } & Correlation & $\begin{array}{c}\text { Lower } \\
\text { limit }\end{array}$ & $\begin{array}{c}\text { Upper } \\
\text { limit }\end{array}$ \\
Bunch et al, 2007 & 0,020 & $-0,037$ & 0,077 \\
Badran et al, 2007 & 0,200 & 0,084 & 0,311 \\
Platonov et al, 2008 & 0,005 & $-0,126$ & 0,136 \\
Lunetta et al, 2009 & 0,130 & 0,006 & 0,250 \\
Ki et al, 2009 & 0,120 & $-0,044$ & 0,278 \\
Wang et al, 2015 & 0,020 & $-0,047$ & 0,087 \\
& 0,050 & 0,014 & 0,087
\end{tabular}

Fig. 5 Correlation between AF and HP

\section{Correlation and $95 \% \mathrm{Cl}$}

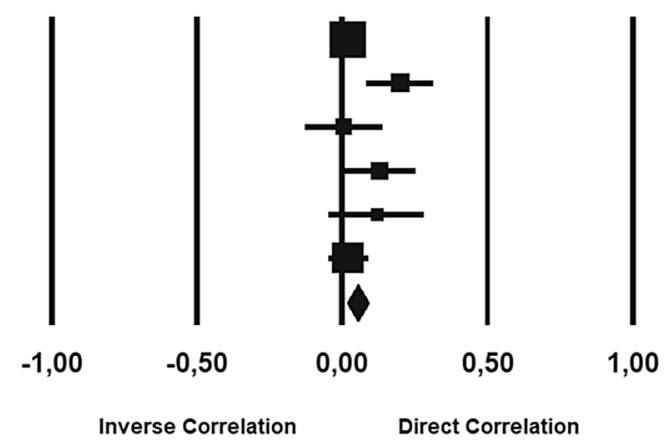

\section{Conclusions}

In conclusion, we did not find any significant correlation between $H$. pylori infection and $\mathrm{AF}$ and, based on our data, it seems unlikely than HP can be considered a risk factor for AF. Further larger research is warranted to establish a potential role of HP in the pathophysiologic development of AF.

Acknowledgements We gratefully acknowledge Judith Wilson for the English Editing of the Manuscript.

Author contributions CT and AM: conception of the study, study selection, collection of data; OP: analysis of data; FM and DJ: quality ratings; MLM and BM: revision of the manuscript for important intellectual content; SG: final approval of the manuscript.

Funding The authors received no financial support for the research and/or authorship of this article.

\section{Compliance with ethical standards}

Conflict of interest The authors declare no conflicts of interest.

OpenAccess This article is distributed under the terms of the Creative Commons Attribution 4.0 International License (http://creativeco mmons.org/licenses/by/4.0/), which permits unrestricted use, distribution, and reproduction in any medium, provided you give appropriate credit to the original author(s) and the source, provide a link to the Creative Commons license, and indicate if changes were made.

\section{References}

1. Abdin A, Yalin K, Lyan E, Sawan N, Liosis S, Meyer-Saraei R, Elsner C, Lange SA, Heeger C-H, Eitel C, Eitel I, Tilz RR (2018) Safety and efficacy of cryoballoon ablation for the treatment of atrial fibrillation in elderly patients. Clin Res Cardiol

2. Bettin M, Dechering D, Kochhauser S, Bode N, Eckardt L, Frommeyer G, Reinke F (2018) Extended ECG monitoring with an implantable loop recorder in patients with cryptogenic stroke: time schedule, reasons for explantation and incidental findings (results from the TRACK-AF trial). Clin Res Cardiol

3. Feyz L, Theuns DA, Bhagwandien R, Strachinaru M, Kardys I, Van Mieghem NM, Daemen J (2018) Atrial fibrillation reduction by renal sympathetic denervation: 12 months' results of the AFFORD study. Clin Res Cardiol

4. Halbfass P, Sonne K, Nentwich K, Ene E, Deneke T (2018) Current developments in cardiac rhythm management devices. Clin Res Cardiol 107:100-104

5. Hooi JKY, Lai WY, Ng WK, Suen MMY, Underwood FE, Tanyingoh D, Malfertheiner P, Graham DY, Wong VWS, Wu JCY, Chan FKL, Sung JJY, Kaplan GG, Ng SC (2017) Global prevalence of helicobacter pylori infection: systematic review and meta-analysis. Gastroenterology 153:420-429

6. Jobs A, Schwind J, Katalinic A, Babaev V, Tilz RR, Rausch S, Thiele H, Eitel I, Eitel C (2018) Prognostic significance of atrial fibrillation in acute decompensated heart failure with reduced versus preserved ejection fraction. Clin Res Cardiol

7. Kottmaier M, Jilek C, Berglar S, Reents T, Bourier F, Semmler V, Telishevska M, Koch-Buttner K, Lengauer S, Kornmayer M, Rousseva E, Brooks S, Hadamitzky M, Kolb C, Hessling G, Deisenhofer I (2018) Exclusion of left atrial thrombus by dualsource cardiac computed tomography prior to catheter ablation for atrial fibrillation. Clin Res Cardiol

8. Liu D, Hu K, Schmidt M, Muntze J, Maniuc O, Gensler D, Oder D, Salinger T, Weidemann F, Ertl G, Frantz S, Wanner C, Nordbeck P (2018) Value of the CHA2DS2-VASc score and fabryspecific score for predicting new-onset or recurrent stroke/TIA in Fabry disease patients without atrial fibrillation. Clin Res Cardiol 107:1111-1121

9. Myrstad M, Malmo V, Ulimoen SR, Tveit A, Loennechen JP (2018) Exercise in individuals with atrial fibrillation. Clin Res Cardiol

10. Prochaska JH, Gobel S, Nagler M, Knopfler T, Eggebrecht L, Lamparter H, Panova-Noeva M, Keller K, Coldewey M, Bickel C, Lauterbach M, Hardt R, Espinola-Klein C, Ten Cate H, Rostock T, Munzel T, Wild PS (2018) Sustained atrial fibrillation increases the risk of anticoagulation-related bleeding in heart failure. Clin Res Cardiol 107:1170-1179

11. Romero R, Gaytan JM, Aguirre A, Llorens P, Gil V, Herrero P, Jacob J, Martin-Sanchez FJ, Perez-Dura MJ, Alquezar A, Lopez ML, Roset A, Peacock WF, Hollander JE, Coll-Vinent B, Miro $\mathrm{O}$ and Group I-SR (2018) The role of atrial fibrillation in the 
short-term outcomes of patients with acute heart failure. Clin Res Cardiol

12. Semmler V, von Krogh F, Haller B, Reents T, Bourier F, Telishevska M, Kottmaier M, Kornmayer M, Brooks S, Koch-Buttner K, Lennerz C, Brkic A, Grebmer C, Blazek P, Weigand S, Hessling G, Kolb C, Deisenhofer I (2018) The incidence, indications and predictors of acute pacemaker implantation after ablation of persistent atrial fibrillation. Clin Res Cardiol

13. Shoaib A, Farag M, Nolan J, Rigby A, Patwala A, Rashid M, Kwok CS, Perveen R, Clark AL, Komajda M, Cleland JGF (2018) Mode of presentation and mortality amongst patients hospitalized with heart failure? A report from the First Euro Heart Failure Survey. Clin Res Cardiol

14. Sramko M, Wichterle D, Melenovsky V, Franekova J, Clemens M, Fukunaga M, Kautzner J (2018) Independent effect of atrial fibrillation on natriuretic peptide release. Clin Res Cardiol

15. Thomas D, Christ T, Fabritz L, Goette A, Hammwohner M, Heijman J, Kockskamper J, Linz D, Odening KE, Schweizer PA, Wakili R, Voigt N, German Cardiac Society Working Group on (2018) Cellular electrophysiology state-of-the-art paper: impact of molecular mechanisms on clinical arrhythmia management. Clin Res Cardiol

16. van den Bruck J-H, Sultan A, Luker J, Thomas D, Willems S, Weinmann K, Kuniss M, Hochadel M, Senges J, Andresen D, Brachmann J, Kuck K-H, Tilz R, Steven D (2018) Remote vs. conventional navigation for catheter ablation of atrial fibrillation: insights from prospective registry data. Clin Res Cardiol

17. Wasmer K, Hochadel M, Wieneke H, Spitzer SG, Brachmann J, Straube F, Tebbenjohanns J, Groschup G, Heisel A, Lewalter T, Senges J, Eckardt L (2018) Long-term symptom improvement and patient satisfaction after AV-node ablation vs. pulmonary vein isolation for symptomatic atrial fibrillation: results from the German Ablation Registry. Clin Res Cardiol

18. Bellmann B, Lin T, Ruppersberg P, Zettwitz M, Guttmann S, Tscholl V, Nagel P, Roser M, Landmesser U, Rillig A (2018) Identification of active atrial fibrillation sources and their discrimination from passive rotors using electrographical flow mapping. Clin Res Cardiol

19. Duerschmied D, Brachmann J, Darius H, Frey N, Katus HA, Rottbauer W, Schafer A, Thiele H, Bode C, Zeymer U (2018) Antithrombotic therapy in patients with non-valvular atrial fibrillation undergoing percutaneous coronary intervention: should we change our practice after the PIONEER AF-PCI and RE-DUAL PCI trials? Clin Res Cardiol 107:533-538

20. Linz D, Arzt M, Sanders P, Bohm M (2018) Should we treat any sleep apnea in patients with atrial fibrillation? Clin Res Cardiol

21. Maurer T, Rottner L, Makimoto H, Reissmann B, Heeger CH, Lemes C, Fink T, Riedl J, Santoro F, Wohlmuth P, Volkmer M, Mathew S, Metzner A, Ouyang F, Kuck KH, Sohns C (2018) The best of two worlds? Pulmonary vein isolation using a novel radiofrequency ablation catheter incorporating contact force sensing technology and 56-hole porous tip irrigation. Clin Res Cardiol

22. Murray MI, Arnold A, Younis M, Varghese S, Zeiher AM (2018) Cryoballoon versus radiofrequency ablation for paroxysmal atrial fibrillation: a meta-analysis of randomized controlled trials. Clin Res Cardiol 107:658-669

23. Omran H, Gutleben KJ, Molatta S, Fischbach T, Wellmann B, Horstkotte D, Korber B, Nolker G (2018) Second generation cryoballoon ablation for persistent atrial fibrillation: an updated meta-analysis. Clin Res Cardiol 107:182-192

24. Pastori D, Miyazawa K, Li Y, Shahid F, Hado H, Lip GYH (2018) Inflammation and the risk of atrial high-rate episodes (AHREs) in patients with cardiac implantable electronic devices. Clin Res Cardiol 107:772-777
25. Desteghe L, Hendriks JML, McEvoy RD, Chai-Coetzer CL, Dendale P, Sanders P, Heidbuchel H, Linz D (2018) The why, when and how to test for obstructive sleep apnea in patients with atrial fibrillation. Clin Res Cardiol 107:617-631

26. Haeusler KG, Groschel K, Kohrmann M, Anker SD, Brachmann J, Bohm M, Diener HC, Doehner W, Endres M, Gerloff C, Huttner HB, Kaps M, Kirchhof P, Nabavi DG, Nolte CH, Pfeilschifter W, Pieske B, Poli S, Schabitz WR, Thomalla G, Veltkamp R, Steiner T, Laufs U, Rother J, Wachter R, Schnabel R (2018) Expert opinion paper on atrial fibrillation detection after ischemic stroke. Clin Res Cardiol 107:871-880

27. Chugh SS, Roth GA, Gillum RF, Mensah GA (2014) Global burden of atrial fibrillation in developed and developing nations. Glob Heart 9:113-119

28. Heeringa J, van der Kuip DA, Hofman A, Kors JA, van Herpen G, Stricker BH, Stijnen T (2006) Lip GY and Witteman JC. Prevalence, incidence and lifetime risk of atrial fibrillation: the Rotterdam study. Eur Heart J 27:949-953

29. Ringborg A, Lindgren P, Jonsson B (2005) The cost-effectiveness of dual oral antiplatelet therapy following percutaneous coronary intervention: a Swedish analysis of the CREDO trial. Eur J Health Econ 6:354-356, (358-62)

30. Kannel WB, Wolf PA, Benjamin EJ, Levy D (1998) Prevalence, incidence, prognosis, and predisposing conditions for atrial fibrillation: population-based estimates. Am J Cardiol 82:2N-9N

31. Zoni-Berisso M, Lercari F, Carazza T, Domenicucci S (2014) Epidemiology of atrial fibrillation: European perspective. Clin Epidemiol 6:213-220

32. Iwasaki YK, Nishida K, Kato T, Nattel S (2011) Atrial fibrillation pathophysiology: implications for management. Circulation 124:2264-2274

33. Guo Y, Lip GY, Apostolakis S (2012) Inflammation in atrial fibrillation. J Am Coll Cardiol 60:2263-2270

34. Anter E, Jessup M, Callans DJ (2009) Atrial fibrillation and heart failure: treatment considerations for a dual epidemic. Circulation 119:2516-2525

35. Ferreira C, Providencia R, Ferreira MJ, Goncalves LM (2015) Atrial fibrillation and non-cardiovascular diseases: a systematic review. Arq Bras Cardiol 105:519-526

36. Gesualdo M, Scicchitano P, Carbonara S, Ricci G, Principi M, Ierardi E, Di Leo A, Cortese F, Ciccone MM (2016) The association between cardiac and gastrointestinal disorders: causal or casual link? J Cardiovasc Med (Hagerstown) 17:330-338

37. Montenero AS, Mollichelli N, Zumbo F, Antonelli A, Dolci A, Barberis M, Sirolla C, Staine T, Fiocca L, Bruno N, O'Connor S (2005) Helicobacter pylori and atrial fibrillation: a possible pathogenic link. Heart 91:960-961

38. Andrew P, Montenero AS (2006) Is Helicobacter pylori a cause of atrial fibrillation? Fut Cardiol 2:429-439

39. Andrew P, Montenero AS (2007) Is there a link between atrial fibrillation and certain bacterial infections? J Cardiovasc Med (Hagerstown) 8:990-996

40. Lunetta M, Fazio G, Avena V, Corrado E, Loredana S, Arnone E, Novo G, Novo S (2009) Helicobacter pylori and atrial fibrillation: absence of correlations. J Cardiovasc Med (Hagerstown) 10:4-5

41. Platonov P, Ekesbo R, Hansson A, Andsberg E, Meurling CJ, Nilsson I, Ljungh A, Wadstrom T, Olsson SB (2008) Permanent atrial fibrillation in patients without structural heart disease is not associated with signs of infection by Chlamydia pneumoniae and Helicobacter pylori. Acta Cardiol 63:479-484

42. Yan J, She Q, Zhang Y, Cui C, Zhang G (2016) The association between arrhythmia and helicobacter pylori Infection: a metaanalysis of case-control studies. Int J Environ Res Public Health 13

43. Liberati A, Altman DG, Tetzlaff J, Mulrow C, Gotzsche PC, Ioannidis JP, Clarke M, Devereaux PJ, Kleijnen J, Moher D (2009) 
The PRISMA statement for reporting systematic reviews and meta-analyses of studies that evaluate health care interventions: explanation and elaboration. J Clin Epidemiol 62:e1-e34

44. Sterne JA, Hernán MA, Reeves BC, Savović J, Berkman ND, Viswanathan M, Henry D, Altman DG, Ansari MT, Boutron I, Carpenter JR, Chan A-W, Churchill R, Deeks JJ, Hróbjartsson A, Kirkham J, Jüni P, Loke YK, Pigott TD, Ramsay CR, Regidor D, Rothstein HR, Sandhu L, Santaguida PL, Schünemann HJ, Shea B, Shrier I, Tugwell P, Turner L, Valentine JC, Waddington H, Waters E, Wells GA, Whiting PF, Higgins JP (2016) ROBINSI: a tool for assessing risk of bias in non-randomised studies of interventions. BMJ 355:i4919

45. Downs SH, Black N (1998) The feasibility of creating a checklist for the assessment of the methodological quality both of randomised and non-randomised studies of health care interventions. J Epidemiol Commun Health 52:377-384

46. Hughes A, Hirsch C, Chalder T, Moss-Morris R (2016) Attentional and interpretive bias towards illness-related information in chronic fatigue syndrome: a systematic review. Br J Health Psychol 21:741-763

47. Byrt T, Bishop J, Carlin JB (1993) Bias, prevalence and kappa. J Clin Epidemiol 46:423-429

48. McHugh ML (2012) Interrater reliability: the kappa statistic. Biochem Med 22:276-282

49. Garza-Gonzalez E, Perez-Perez GI, Maldonado-Garza HJ, Bosques-Padilla FJ (2014) A review of Helicobacter pylori diagnosis, treatment, and methods to detect eradication. World J Gastroenterol 20:1438-1449

50. Higgins JPT, Thompson SG, Deeks JJ, Altman DG (2003) Measuring inconsistency in meta-analyses. BMJ Br Med J 327:557-560

51. Schmidt F, Hunter LJE (2015) Methods of metha-analysis. SAGE, Thausand Oaks

52. Bunch TJ, Day JD, Anderson JL, Horne BD, Muhlestein JB, Crandall BG, Weiss JP, Lappe DL, Asirvatham SJ (2008) Frequency of helicobacter pylori seropositivity and C-reactive protein increase in atrial fibrillation in patients undergoing coronary angiography. Am J Cardiol 101:848-851

53. Badran HM, Mahfouz ME (2007) Cytotoxin-associated gene-A bearing strains of Helicobacter pylori and atrial fibrillation due to ischemic origin: is there a link? Eur J Cardiovasc Prev Rehabil 14:518-520

54. Ki M-R, Shin D-G, Park J-S, Hong K-S, Hong I-H, Park J-K, Jeong K-S (2010) Frequency of vacuolating cytotoxin A (VacA)positive Helicobacter pylori seropositivity and TGF-beta1 decrease in atrial fibrillation. Int J Cardiol 145:345-346

55. Franceschi F, Brisinda D, Buccelletti F, Ruggieri MP, Gasbarrini A, Sorbo A, Marsiliani D, Venuti A, Fenici P, Gasbarrini G, Silveri NG, Fenici R (2013) Prevalence of virulent Helicobacter pylori strains in patients affected by idiopathic dysrhythmias. Intern Emerg Med 8:333-337

56. Wang D-Z, Chen W, Yang S, Wang J, Li Q, Fu Q, Li S-J, Chen B-X (2015) Helicobacter pylori infection in Chinese patients with atrial fibrillation. Clin Interv Aging 10:813-819
57. de Martel C, Ferlay J, Franceschi S, Vignat J, Bray F, Forman D, Plummer M (2012) Global burden of cancers attributable to infections in 2008: a review and synthetic analysis. Lancet Oncol 13:607-615

58. Suerbaum S, Michetti $\mathrm{P}$ (2002) Helicobacter pylori infection. $\mathrm{N}$ Engl J Med 347:1175-1186

59. Boos CJ, Anderson RA, Lip GYH (2006) Is atrial fibrillation an inflammatory disorder? Eur Heart J 27:136-149

60. Psychari SN, Apostolou TS, Sinos L, Hamodraka E, Liakos G, Kremastinos DT (2005) Relation of elevated C-reactive protein and interleukin-6 levels to left atrial size and duration of episodes in patients with atrial fibrillation. Am J Cardiol 95:764-767

61. Chung MK, Martin DO, Sprecher D, Wazni O, Kanderian A, Carnes CA, Bauer JA, Tchou PJ, Niebauer MJ, Natale A, Van Wagoner DR (2001) C-reactive protein elevation in patients with atrial arrhythmias: inflammatory mechanisms and persistence of atrial fibrillation. Circulation 104:2886-2891

62. Marcus GM, Whooley MA, Glidden DV, Pawlikowska L, Zaroff JG, Olgin JE (2008) Interleukin-6 and atrial fibrillation in patients with coronary artery disease: data from the Heart and Soul Study. Am Heart J 155:303-309

63. Goette A, Kalman JM, Aguinaga L, Akar J, Cabrera JA, Chen SA, Chugh SS, Corradi D, D'Avila A, Dobrev D, Fenelon G, Gonzalez M, Hatem SN, Helm R, Hindricks G, Ho SY, Hoit B, Jalife J, Kim Y-H, Lip GYH, Ma C-S, Marcus GM, Murray K, Nogami A, Sanders P, Uribe W, Van Wagoner DR, Nattel S (2016) Document reviewers: Osmar A. Centurion K-HKKKPJLSMSJHS, Gaurav AU and Review coordinator: Alena S. EHRA/HRS/APHRS/SOLAECE expert consensus on Atrial cardiomyopathies: definition, characterisation, and clinical implication. J Arrhythm 32:247-278

64. Mishima RS, Elliott AD, Sanders P, Linz D (2018) Microbiome and atrial fibrillation. Int J Cardiol 255:103-104

65. Yu L, Meng G, Huang B, Zhou X, Stavrakis S, Wang M, Li X, Zhou L, Wang Y, Wang M, Wang Z, Deng J, Po SS, Jiang H (2018) A potential relationship between gut microbes and atrial fibrillation: Trimethylamine $\mathrm{N}$-oxide, a gut microbe-derived metabolite, facilitates the progression of atrial fibrillation. Int J Cardiol 255:92-98

66. Hatzinikolaou-Kotsakou E, Tziakas D, Hotidis A, Stakos D, Floros D, Papanas N, Chalikias G, Maltezos E, Hatseras DI (2006) Relation of C-reactive protein to the first onset and the recurrence rate in lone atrial fibrillation. Am J Cardiol 97:659-661

67. Andersen LP (2007) Colonization and Infection by Helicobacter pylori in Humans. Helicobacter 12:12-15

68. Morillo CA, Banerjee A, Perel P, Wood D, Jouven X (2017) Atrial fibrillation: the current epidemic. J Geriatr Cardiol JGC 14:195-203

69. Chugh SS, Havmoeller R, Narayanan K, Singh D, Rienstra M, Benjamin EJ, Gillum RF, Kim Y-H, McAnulty JH, Zheng Z-J, Forouzanfar MH, Naghavi M, Mensah GA, Ezzati M, Murray CJL (2014) Worldwide epidemiology of atrial fibrillation. Circulation 129:837-847 